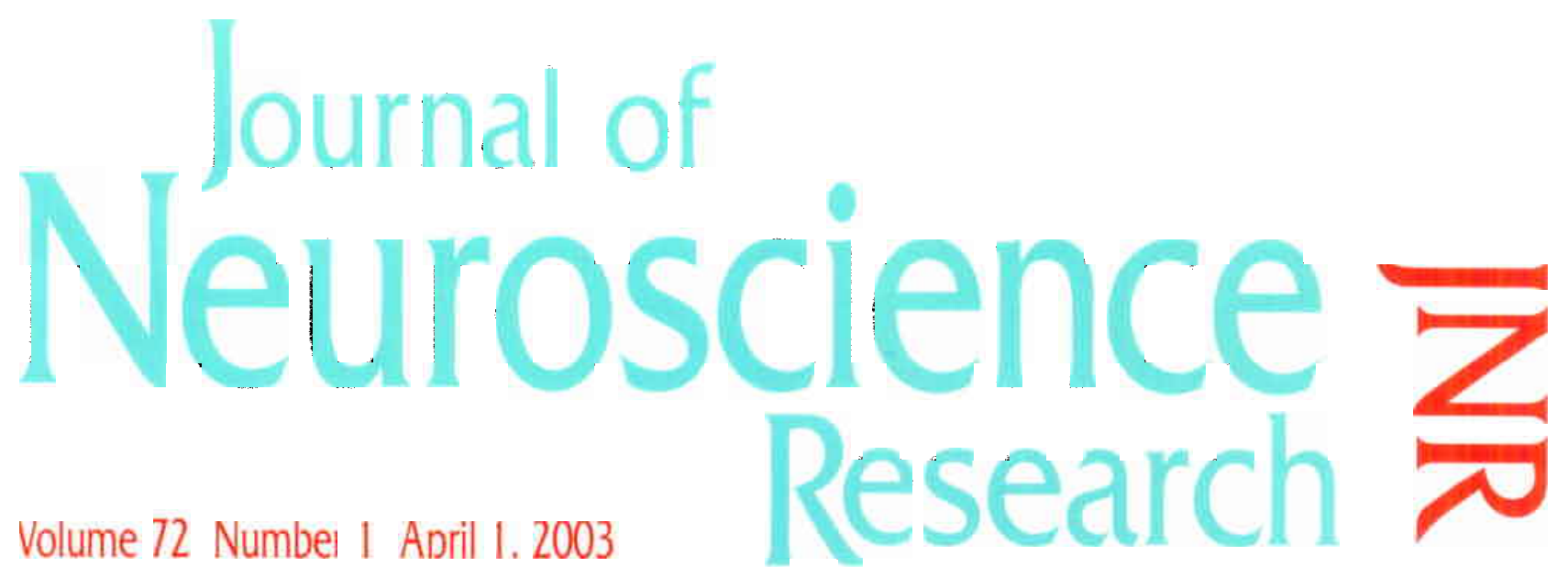

Published online 15 anuary 19 February 2003

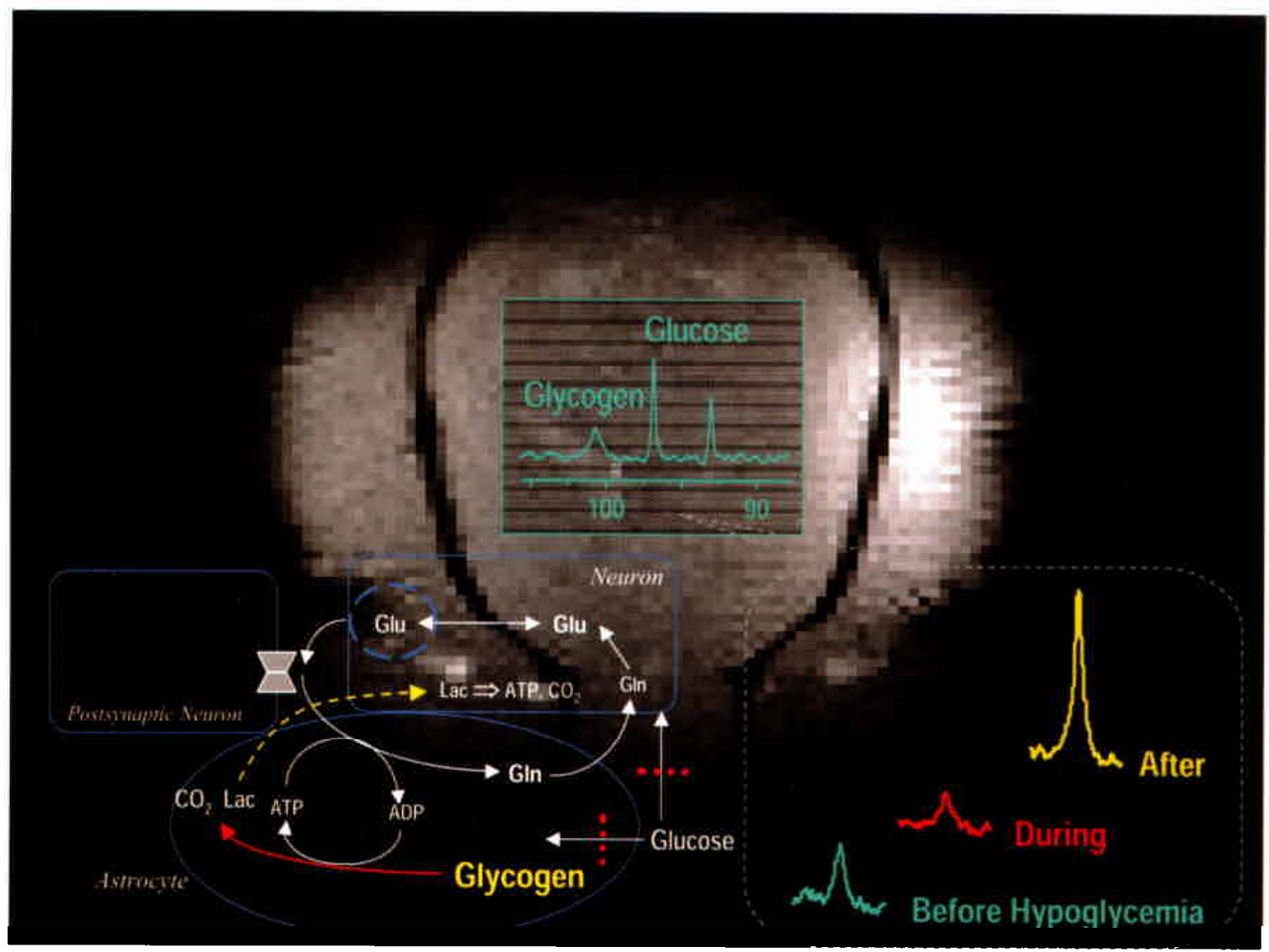




\title{
Effect of Hypoglycemia on Brain Glycogen Metabolism In Vivo
}

\author{
In-Young Choi, ${ }^{1}$ Elizabeth R. Seaquist, ${ }^{2}$ and Rolf Gruetter ${ }^{1,3 \star}$ \\ ${ }^{1}$ Department of Radiology, Center for Magnetic Resonance Research, University of Minnesota Medical School, \\ Minneapolis, Minnesota \\ ${ }^{2}$ Department of Medicine, University of Minnesota Medical School, Minneapolis, Minnesota \\ ${ }^{3}$ Department of Neuroscience, University of Minnesota Medical School, Minneapolis, Minnesota
}

The brain contains a small but significant amount of glycogen, which has long been considered to play an insignificant role in the brain. In this study, brain glycogen metabolism was measured using ${ }^{13} \mathrm{C}$ NMR spectroscopy at 9.4 T. Brain glycogen metabolism was modulated by hyperinsulinemia resulting in a net accumulation. The role of glycogen in maintaining brain function is unknown; one possibility is that it may serve as an endogenous glucose reservoir to protect the brain against severe hypoglycemia. To address this possibility, rats were subjected to insulin-induced moderate hypoglycemia and when the level of brain glucose approached zero, brain glycogen content began to decrease gradually, demonstrating utilization of this glucose reservoir. The brain glycogen signal never became undetectable, however, even during $2 \mathrm{hr}$ of hypoglycemia. When plasma and brain glucose concentrations were restored, glycogen increased and the concentration exceeded the prehypoglycemic level by several-fold. The data suggest that brain glycogen can provide fuel for extended periods of time when glucose supply is inadequate. Furthermore, brain glycogen can rebound (super-compensate) after a single episode of hypoglycemia. We postulate that brain glycogen serves as an energy store during hypoglycemia and that it may participate in the creation of reduced physiological responses to hypoglycemia that are involved in a symptom often observed in patients with diabetes, hypoglycemia unawareness.

() 2003 Wiley-Liss, Inc.

Key words: NMR; brain; glycogen; super-compensation; hypoglycemia unawareness

A continuous supply of glucose from the blood is considered essential for normal brain function. When a sudden fall in plasma glucose occurs, the brain is protected normally against hypoglycemia through a number of autonomic counterregulatory responses, including the inhibition of insulin secretion and the sequential release of glucagon, epinephrine, norepinephrine, cortisol (ACTH) and growth hormone (Gerich et al., 1991; Mitrakou et al., 1991). Patients with Type 1 diabetes mellitus, however, develop defective counterregulatory hormone responses over time and glucose thresholds that elicit the counterregulatory responses are lowered by antecedent hypoglycemia. Eventually, patients with frequent hypoglycemia may develop reduced physiological responses to hypoglycemia and lose their ability to detect and protect against hypoglycemia until they develop frank neuroglycopenia (insufficient glucose supply to the brain) leading to hypoglycemia unawareness (Cryer, 1994).

How the brain adapts to recurrent abnormalities in serum glucose levels is not clear. Over the past 20 years, it has been suggested that glucose transport at the bloodbrain barrier is up- or downregulated during chronic alterations of glycemia, and the alterations in glucose transport might be a mechanism involved in impaired recognition of hypoglycemia (Pelligrino et al., 1992; Boyle et al., 1994; Kumagai et al., 1995; Amiel, 1998; Simpson et al., 1999). These observations on the effect of hyper- and hypoglycemia on glucose transport are conflicting, however, and it is therefore possible that the brain adapts to alterations in glycemia through more than one mechanism.

One alternative mechanism through which the brain may adapt to hypoglycemia could include changes in brain glycogen metabolism. Glycogen is an endogenous carbohydrate store for energy metabolism in many tissues and can be utilized increasingly when glucose supply is limited. Brain glycogen has been suggested as a source of glucose for the brain under extreme conditions (Clarke and

Contract grant sponsor: NIH; Contract grant numbers: R21DK58004, R01NS42005; Contract grant sponsor: Juvenile Diabetes Research Foundation International; Contract grant sponsor: University of Minnesota Graduate School; Contract grant sponsor: NCRR; Contract grant number: P41RR08079; Contract grant sponsor: W.M. Keck Foundation.

Current address for I.-Y. Choi is: Nathan Kline Institute, Medical Physics, 140 Old Orangeburg Road, Orangeburg, NY 10962.

^Correspondence to: Rolf Gruetter, Center for Magnetic Resonance Research, 2021 6th Street SE, Minneapolis, MN 55455.

E-mail: gruetter@cmrr.umn.edu

Received 12 August 2002; Revised 10 December 2002; Accepted 16 December 2002 
Sokoloff, 1999). It has been considered generally, however, that brain glycogen stores are inadequate to meet all basal metabolic demands based on reported cerebral glycogen concentrations on the order of a few $\mu \mathrm{mol} / \mathrm{g}$, which can supply the glucose required for basal metabolism for at most a few minutes during anoxia and aglycemia (Clarke and Sokoloff, 1999). During anoxia, glycogen is a less significant source of energy (ATP synthesis) due to the lower energetic yield of anaerobic metabolism (16fold), than during aglycemia. Furthermore, the deficit in glucose supply is expected to be gradual with a transition from adequate to increasingly inadequate glucose transport. Recent reports have suggested that brain glucose transport across the brain has a rather low $\mathrm{K}_{\mathrm{m}}$ (Gruetter et al., 1998b; Choi et al., 2001) consistent with that of the major transporter isoform at the blood-brain barrier, GLUT-1, which implies that a mismatch between glucose supply and demand occurs during hypoglycemia only at relatively low plasma glucose concentrations (Choi et al., 2001) and that this mismatch is gradual. The role of brain glycogen as a significant glucose reservoir is supported further by the observations that a limited reduction in the concentration of glycogen occurred during hypoglycemia (Kerr and Ghantus, 1936) and that endogenous cerebral carbohydrate stores are used as substrates for metabolism in hypoglycemia (Lewis et al., 1974; Norberg and Siesjo, 1976).

In most tissues, glycogen metabolism is sensitive to alterations in plasma glucose and insulin concentrations (van de Werve and Jeanrenaud, 1987; Richter et al., 2001), which was observed in cell cultures (Dringen and Hamprecht, 1992; Swanson and Choi, 1993) and some evidence also supports this for the brain (Nelson et al., 1968; Strang and Bachelard, 1971; Daniel et al., 1977). In addition, glycogen has been shown to replete to levels higher than the predepletion levels in tissues such as muscle, liver, and heart when ample substrate and hormones are present during recovery. This rebound in glycogen content has been termed "super-compensation" (Poland and Trauner, 1973; Gorski et al., 1976). Supercompensation of brain glycogen has also been reported after an ischemic episode (Folbergrova et al., 1996). This suggests that super-compensation is a general feature of glycogen metabolism.

We demonstrated recently (Choi et al., 1999, 2000) that brain glycogen metabolism can be measured in vivo using direct ${ }^{13} \mathrm{C}$ nuclear magnetic resonance (NMR) detection in conjunction with infusion of ${ }^{13} \mathrm{C}$-labeled glucose. We employed these methods to test the hypothesis that brain glycogen serves as a source of energy during periods of hypoglycemia. We sought to determine: 1) whether brain glycogen metabolism can be affected by changes in plasma insulin concentrations; 2 ) whether brain glycogen is a significant source of glucosyl units during insulin-induced hypoglycemia; and 3) whether brain glycogen concentrations can super-compensate after a single episode of hypoglycemia.

\section{MATERIALS AND METHODS}

\section{Animals}

The study was approved and conducted according to guidelines for the care and use of laboratory animals at the University of Minnesota. Male Sprague-Dawley rats $(258 \pm 8 \mathrm{~g}$, mean \pm SE, $n=20$ ) were studied after fasting overnight with free access to water. Animals were anesthetized using 2\% isoflurane (Marsam Pharmaceuticals, Cherry Hill, NJ) in a 1:1 mixture of nitrous oxide $\left(\mathrm{N}_{2} \mathrm{O}\right)$ and oxygen $\left(\mathrm{O}_{2}\right)$ gases for surgery. The animals were then intubated and ventilated with a pressuredriven ventilator (Kent Scientific, Litchfield, CT). Catheters were inserted into both femoral arteries for blood gases, glucose analyses, and monitoring of arterial blood pressure. Two additional catheters were inserted into both femoral veins for intravenous infusion of $\alpha$-chloralose, glucose, insulin and somatostatin. Arterial blood pressure, respiratory rate and pattern were monitored continuously with a multi-trace recorder (AcqKnowledge, Biopak, CA). End tidal $\mathrm{CO}_{2}$ also was monitored continuously during surgery and experiments with a capnometer (SC-300; BCI International, Waukesha, WI).

Immediately after surgery, anesthesia was switched to $\alpha$-chloralose, which was administered as follows: $40 \mathrm{~min}$ after a $40 \mathrm{mg} / \mathrm{kg}$ bolus injection, a continuous i.v. infusion was started $(24-26.7 \mathrm{mg} / \mathrm{kg} / \mathrm{hr}$ ) as in our previous study (Choi et al., 2001). The animals were secured using a home-built Delrin holder with a bite bar and two ear inserts to provide a fixed position of the skull. The animal was then placed in an acrylic holder attached to an insert in the gradient coil, which ensured stability of the experimental setup for extended measuring times. Body temperature was maintained at $37.0 \pm 0.5^{\circ} \mathrm{C}$ with a warm water circulation system based on a feedback obtained from a rectal temperature probe (Cole Palmer, Vernon Hills, IL).

The study was conducted in two groups of animals. In the first group of animals $(n=12)$, the effect of insulin on brain glycogen metabolism was assessed. In these animals, the preparation was identical to that described previously (Choi et al., $1999,2001)$ and $99 \%$-enriched $\left[1-{ }^{13} \mathrm{C}\right] \mathrm{D}$-glucose $(20 \% \mathrm{wt} / \mathrm{vol}$ solution, Isotec Inc., Miamisburg, $\mathrm{OH}$ ) was infused into the left femoral vein according to an infusion protocol described previously (Choi et al., 1999). Glucose concentrations in the brain were measured continuously by ${ }^{13} \mathrm{C}$ NMR and maintained at approximately $3 \mu \mathrm{mol} / \mathrm{g}$ for $4 \mathrm{hr}$ by adjusting the rate of the glucose infusion accordingly. While infusing glucose, insulin was infused at $6 \mathrm{IU} / \mathrm{kg} / \mathrm{hr}$ to induce hyperinsulinemia in six animals; in the other six animals, somatostatin was infused at $0.7-0.8 \mu \mathrm{g} / \mathrm{kg} / \mathrm{min}$ to suppress pancreatic $\beta$ cell function and to minimize plasma insulin concentrations (Rossetti et al., 1993).

The second group of animals $(n=8)$ was used to assess the effect of hypoglycemia on brain glycogen metabolism. These animals were treated initially in the same manner as animals in Group I, except that no exogenous hormone was administered. The brain glucose concentration was maintained at $\sim 3 \mu \mathrm{mol} / \mathrm{g}$ before and after hypoglycemia in all experiments. To induce hypoglycemia, insulin (24-40 IU/kg, Humulin R, Eli Lilly \& Co., Indianapolis, IN) was administrated intravenously and the $\left[1-{ }^{13} \mathrm{C}\right]$ glucose infusion rate was reduced to $0.2 \mathrm{mg} / \mathrm{min}$. The degree and duration of hypoglycemia (below $2 \mathrm{mM}$ plasma glucose concentration for approximately $2 \mathrm{hr}$ measured in a 
nearby glucose analyzer every $10-15 \mathrm{~min}$ ) were controlled by concomitant measurements of brain and plasma glucose levels, and designed to avoid any extensive damage to brain tissue. This was confirmed by stable amino acid concentrations during hypoglycemia using localized ${ }^{1} \mathrm{H}$ NMR spectroscopy $(n=3)$. Arterial blood was withdrawn through Teflon tubing lines (Spectrum Chromatography, Houston, TX) for blood gas analysis. Physiological parameters were maintained within normal range at $\mathrm{pCO}_{2}=39.9 \pm 1.6 \mathrm{~mm} \mathrm{Hg}, \mathrm{pO}_{2}=186.4 \pm 15.1 \mathrm{~mm}$ $\mathrm{Hg}$ and arterial $\mathrm{pH}=7.4 \pm 0.02$.

\section{NMR Methods}

All experiments were carried out on a 9.4-T, 31-cm horizontal-bore magnet (Magnex Scientific, UK), interfaced to a Varian INOVA console (Palo Alto, CA). An actively shielded gradient coil (Magnex Scientific, Abingdon, UK) with an 11-cm inner diameter was used and a home-built quadrature ${ }^{1} \mathrm{H}$ surface RF coil (14-mm diameter) and a linear polarized threeturn ${ }^{13} \mathrm{C}$ coil (12-mm diameter) were used as a transceiver for ${ }^{1} \mathrm{H}$ NMR and ${ }^{13} \mathrm{C}$ NMR as described previously (Adriany and Gruetter, 1997). A $99 \%{ }^{13} \mathrm{C}$-enriched formic acid sphere was located at the center of the ${ }^{13} \mathrm{C}$ coil as an external reference and the coil was placed on the animal's head (Choi et al., 2000). Automated localized shimming with a fully adiabatic version of FAST(EST)MAP was used (Gruetter and Tkac, 2000). The full width at half-maximum of the in vivo water signal was about 20 $\mathrm{Hz}$ in a nominal $510 \mu \mathrm{l}$ volume $\left(8.5 \times 6 \times 10 \mathrm{~mm}^{3}\right)$. The volume of interest (VOI) was placed in the rat brain to avoid signal contamination from extra-cerebral tissues as demonstrated previously (Choi et al., 1999, 2000). The efficiency of threedimensional localization was verified continuously from the absence of the $30.5 \mathrm{ppm}$ natural abundance lipid signal in spectra optimized for the amino acid region (20-40 ppm) acquired in an interleaved fashion with spectra optimized for the detection of glycogen and glucose C1 signals, as the lipid signals are not detectable in the normal brain.

\section{Quantification of NMR Signals}

The ${ }^{13} \mathrm{C}$ NMR signals of brain glycogen and glucose were quantified using the external reference method (Gruetter et al., 1998a; Choi et al., 1999). In brief, in vivo ${ }^{13} \mathrm{C}$ NMR signals of glycogen and glucose were quantified by comparison with the measurements of phantoms containing $\sim 400 \mathrm{mM}$ natural abundance oyster glycogen and $0.9 \mathrm{mM}$ of $99 \%$-enriched $\left[1-{ }^{13} \mathrm{C}\right]$ D-glucose after correction for the effects of loading and nuclear Overhauser effect on the NMR signals.

In addition, ${ }^{1} \mathrm{H}$ NMR spectra were acquired in three animals for quantification of brain glucose and amino acid concentrations such as NAA, glutamate, glutamine, and aspartate in conjunction with unlabeled glucose infusion. Glucose quantification was carried out by frequency domain analysis with LCModel (Pfeuffer et al., 1999) from a $150 \mu l$ volume in the brain. A STEAM sequence was used with $2-m s e c$ echo time, 5 -sec repetition time, and $20 \mathrm{msec}$ mixing time (Tkac et al., 1999).

\section{RESULTS}

The experiments carried out in the first group addressed the question of whether insulin alone has an effect on

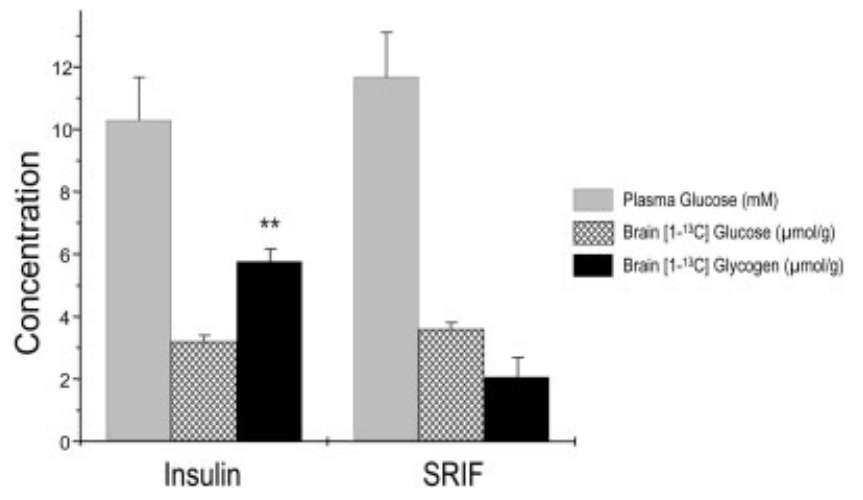

Fig. 1. Effect of insulin on brain glycogen metabolism. Increased ${ }^{13} \mathrm{C}$ label incorporation into brain glycogen was observed during insulin infusion (left, $n=6$ ) compared to the somatostatin (SRIF) infusion (right, $n=6)(\star \star P<0.001)$. In both groups, glucose concentrations in the brain and plasma were maintained constant. Error bars indicate standard deviation. Measurements were carried out after four hours of intravenous infusion of $\left[1-{ }^{13} \mathrm{C}\right]$ glucose, while administering insulin $(6$ $\mathrm{IU} / \mathrm{kg} / \mathrm{hr})$ in one group and somatostatin $(0.7-0.8 \mu \mathrm{g} / \mathrm{kg} / \mathrm{min})$ in the other.

brain glycogen metabolism. In these animals, the amount of ${ }^{13} \mathrm{C}$ label incorporated into glycogen was measured after $4 \mathrm{hr}$ of ${ }^{13} \mathrm{C}$ glucose infusion with either intravenous infusion of insulin $(6 \mathrm{IU} / \mathrm{kg} / \mathrm{hr})$ or somatostatin $(0.7-0.8$ $\mu \mathrm{g} / \mathrm{kg} / \mathrm{min})$. Somatostatin effectively suppresses endogenous insulin secretion, which was evident in our experiments by the greatly reduced glucose infusion rate required to maintain constant plasma glucose concentrations. Plasma glucose concentrations were $10.3 \pm$ $1.4 \mathrm{mM}$ (mean $\pm \mathrm{SD}, n=6$ ) for the insulin group and $11.7 \pm 2.1 \mathrm{mM}$ (mean $\pm \mathrm{SD}, n=6$ ) for the somatostatin group, resulting in brain glucose concentrations of $3.4 \pm 0.5 \mu \mathrm{mol} / \mathrm{g}$ and $3.8 \pm 0.4 \mu \mathrm{mol} / \mathrm{g}$, respectively. After $4 \mathrm{hr}$ of ${ }^{13} \mathrm{C}$-labeled glucose infusion, the concentration of $\left[1-{ }^{13} \mathrm{C}\right]$ glycogen was $5.8 \pm 0.4$ $\mu \mathrm{mol} / \mathrm{g}$ when infusing insulin, whereas the glycogen C1 concentration was only $2.1 \pm 0.6 \mu \mathrm{mol} / \mathrm{g}(n=6$, $P<0.0001$ ) when infusing somatostatin alone (Fig. 1).

In the second group of animals, the effect of hypoglycemia on brain glycogen metabolism was assessed. In these studies, brain glucose was clamped at $3.2 \pm 0.2$ $\mu \mathrm{mol} / \mathrm{g}$ (mean $\pm \mathrm{SE}, n=8$ ) for at least $4 \mathrm{hr}$ while infusing $99 \%$ enriched $\left[1-{ }^{13} \mathrm{C}\right]$ glucose. Clamping glucose resulted in very stable brain glucose signals after an initial short equilibration period (Fig. 2A, top stack plot), consistent with a stable plasma glucose concentration. The initial labeling of glycogen $\mathrm{C} 1$ from ${ }^{13} \mathrm{C}$-labeled glucose led to an appreciable glycogen $\mathrm{C} 1$ signal (Fig. 2A, bottom stack plot), corresponding to a concentration of $\left[1-{ }^{13} \mathrm{C}\right]$ glycogen of $3.6 \pm 0.2 \mu \mathrm{mol} / \mathrm{g}$ (mean $\pm \mathrm{SE}$ ). After a primedcontinuous administration of $24-40 \mathrm{IU} / \mathrm{kg}$ of insulin (the start of which is indicated by the arrow in Fig. 2A) and a drastic reduction in the $\left[1-{ }^{13} \mathrm{C}\right]$ glucose infusion rate to 0.2 $\mathrm{mg} / \mathrm{min}$, the brain glucose concentration decreased as a 


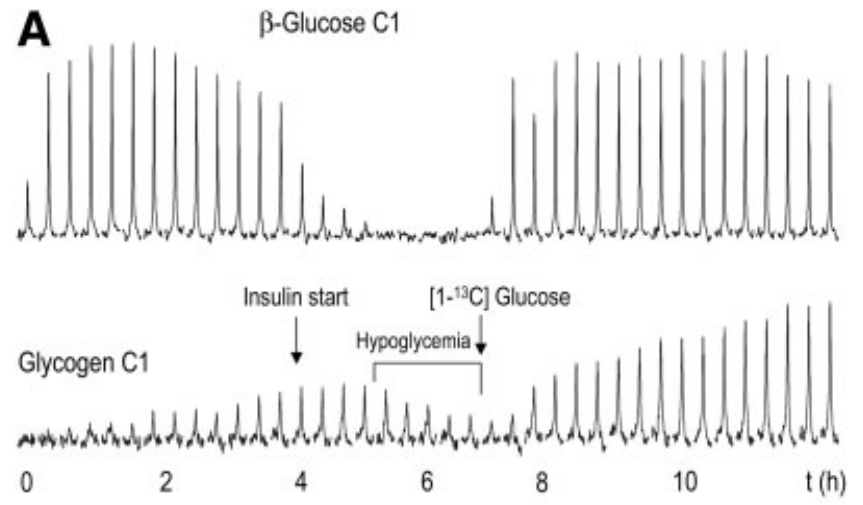

Fig. 2. Time-resolved changes of $\left[1-{ }^{13} \mathrm{C}\right]$ cerebral glycogen and glucose signals during insulin-induced hypoglycemia. A: A horizontal stack plot of three-dimensional localized ${ }^{13} \mathrm{C}$ NMR spectra of the rat brain showing the glycogen $\mathrm{C} 1$ signals (bottom) and the $\beta$-glucose $\mathrm{C} 1$ signals (top trace). Each spectrum corresponds to $12 \mathrm{~min}$ of data accumulation, and all spectra are from the same animal $(\mathrm{LB}=20 \mathrm{~Hz})$. The start of insulin infusion is indicated by the arrow, which was ended when the ${ }^{13} \mathrm{C}$ glucose concentration was restored. Hypoglycemia,

result of the ensuing hypoglycemia. The plasma glucose concentration was below $2 \mathrm{mM}$ for $2 \mathrm{hr}$.

During hypoglycemia, the glycogen C1 signal decreased discernibly, presumably due to decreased synthase activity and increased phosphorylase activity. The decrease in glycogen C1 started when brain glucose concentration was $0.1 \pm 0.1 \mu \mathrm{mol} / \mathrm{g}$. Once the brain glucose concentration was close to zero, brain glycogen C1 decreased with a rate of $-64 \pm 8 \% / \mathrm{hr}$ (mean $\pm \mathrm{SE}, n=8$ ) of the pre-hypoglycemic $\left[1-{ }^{13} \mathrm{C}\right]$ glycogen signal. Even after $2 \mathrm{hr}$ of hypoglycemia, the brain glycogen $\mathrm{C} 1$ signal was detectable and we were unable to note complete elimination (Fig. 2).

Hypoglycemia was terminated by stopping the insulin infusion and increasing the rate of the $\left[1-{ }^{13} \mathrm{C}\right]$ glucose infusion to restore the plasma glucose concentration to the pre-hypoglycemia level, resulting in a $3.3 \pm 0.1 \mu \mathrm{mol} / \mathrm{g}$ brain glucose concentration. The brain glycogen C1 signal started to increase immediately at an initial rate of $1.9 \pm$ $0.4 \mu \mathrm{mol} / \mathrm{g} / \mathrm{hr}$ (mean $\pm \mathrm{SE}, n=8$ ). Glycogen C1 continued to rise and reached $6.8 \pm 0.7 \mu \mathrm{mol} / \mathrm{g}$ (mean $\pm \mathrm{SE}$, $n=7) 4 \mathrm{hr}$ after glucose supply had been restored, and amounted to a level that was $153 \pm 30 \%$ above basal $(P<$ 0.01, $n=5$, Fig. 3B) $7 \mathrm{hr}$ after ending hypoglycemia. In several cases, glycogen concentrations were more than 10 $\mu \mathrm{mol} / \mathrm{g}$ and continued to rise (Fig. 2B).

Figure $3 \mathrm{~A}$ shows representative spectra of the glycogen and glucose region before (top), during (middle), and after hypoglycemia (bottom) of the rat brain. Each spectrum was acquired $4 \mathrm{hr}$ after the start of ${ }^{13} \mathrm{C}$ glucose

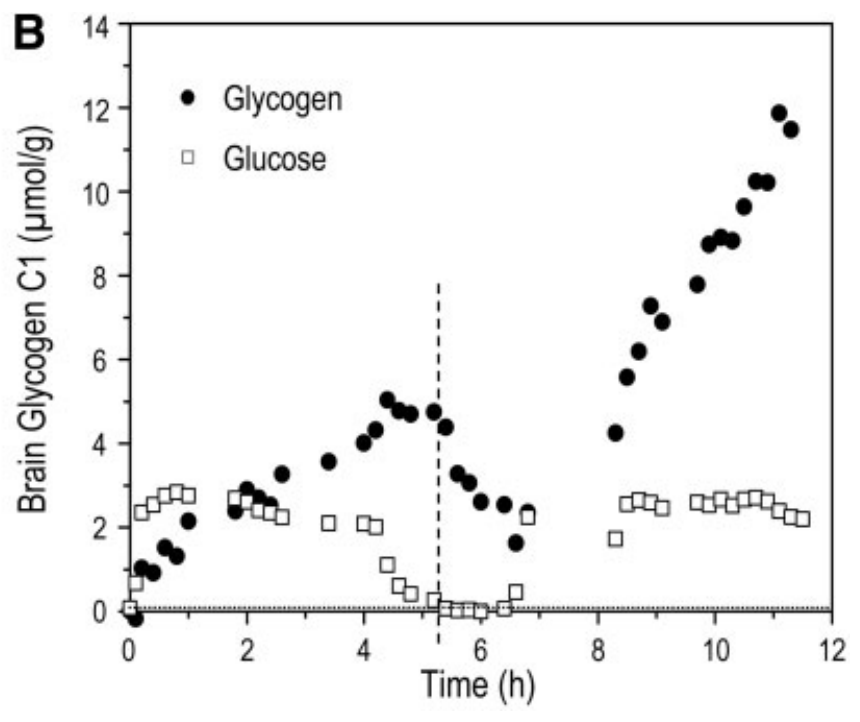

indicated by the bracket, was the time during which the brain glucose signal was within the noise. B: Time-course of the quantified glycogen C1 and glucose C1 signals. Data are from the same animal as in (A). During hypoglycemia, plasma glucose concentration was below $2 \mathrm{mM}$ for $2 \mathrm{hr}$ and brain glucose concentration was below $0.1 \mu \mathrm{mol} / \mathrm{g}$ as indicated by the horizontal dotted line. The vertical dashed line indicates the start of glycogenolysis during hypoglycemia, which coincided with the time point where brain glucose approached zero.

infusion (top), $\sim 2 \mathrm{hr}$ after the start of insulin infusion for hypoglycemia (middle) and $\sim 4 \mathrm{hr}$ after the restart of ${ }^{13} \mathrm{C}$ glucose infusion to restore the plasma glucose concentration to the pre-hypoglycemia level (bottom), respectively. During hypoglycemia, the glycogen C1 signal was decreased, but clearly visible at $100.6 \mathrm{ppm}$, whereas glucose signals were not detectable. After hypoglycemia, a distinctive increase of the glycogen C1 signal was observed whereas the intensity of glucose signals remained the same as during the pre-hypoglycemic period (Fig. 3A, bottom).

Sequentially-acquired localized ${ }^{1} \mathrm{H}$ NMR spectroscopy was used to assess whether any major changes in amino acid concentrations or energy phosphates (PCr) occurred during the specific hypoglycemic protocol used in this study. These preliminary measurements indicated that the concentrations of creatine, phosphocreatine, and amino acids such as aspartate and glutamate did not change by more than $10 \%$.

\section{DISCUSSION}

This study demonstrated that brain glycogen metabolism varied with changes in plasma insulin. An episode of insulin-induced hypoglycemia led to a depletion of brain glycogen whereas restoration of glycemia led to supercompensation in brain glycogen content. These observations suggest that brain glycogen may serve as a source of glucosyl units during insulin-induced hypoglycemia and suggest that brain glycogen may play a more important role in metabolism than was assumed previously. 


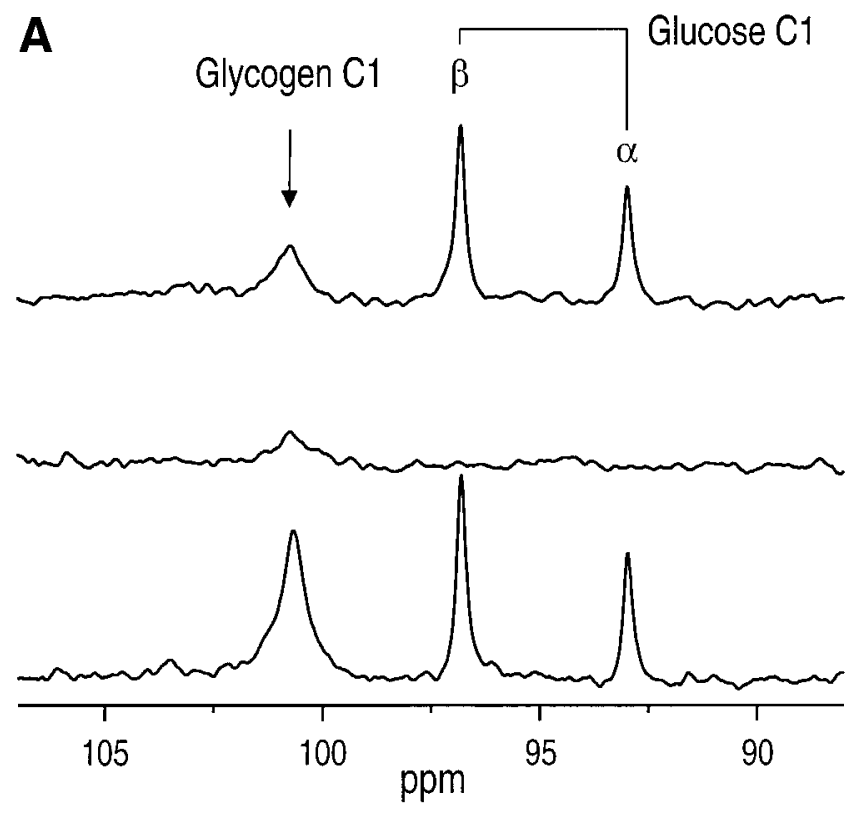

Fig. 3. Super-compensation of brain glycogen concentration. A: A stack plot of glycogen and glucose signals measured before, during and after hypoglycemia. The three-dimensional localized ${ }^{13} \mathrm{C}$ NMR spectra show the signal changes of glycogen and glucose before (top), during (middle) and after (bottom) hypoglycemic periods. The corresponding resonances of glycogen and glucose in the brain were at $100.6 \mathrm{ppm}$ (glycogen C1), $92.96 \mathrm{ppm}(\alpha$-glucose C1) and $96.80 \mathrm{ppm}(\beta$-glucose $\mathrm{C} 1)$, respectively. Each spectrum corresponds to $10 \mathrm{~min}$ of data accu-

\section{Assessment of Insulin Effects on Brain Glycogen}

In the insulin-treated group, the amount of ${ }^{13} \mathrm{C}$ label incorporated into glycogen was three-fold higher than in the somatostatin-treated group, where insulin secretion was suppressed (Fig. 1). Because the plasma and brain glucose concentrations in both groups were very similar, this result suggests that plasma insulin alone has a strong effect on brain glycogen metabolism. The amount of label in glycogen in the group receiving insulin exceeded the normal brain glycogen concentration, which demonstrates an increase in brain glycogen content. It has been reported previously that brain glycogen increases $1 \mathrm{hr}$ after insulin administration (Daniel et al., 1977). Our results were obtained at a much lower plasma glucose concentration than the studies by Daniel et al. (1977), thus supporting the notion that brain glycogen provides an aspect of in vivo cerebral carbohydrate metabolism that is sensitive to changes in plasma insulin.

\section{Effect of Hypoglycemia on Brain Glycogen Metabolism}

During insulin-induced hypoglycemia, degradation of brain $\left[1-{ }^{13} \mathrm{C}\right]$ glycogen started when brain glucose concentrations were $0.1 \pm 0.1 \mu \mathrm{mol} / \mathrm{g}$, which is close to the $\mathrm{K}_{\mathrm{m}}$ of hexokinase. This is also the point where we observed that glucose transport became rate limiting for metabolism and when CBF was increased acutely (Choi et

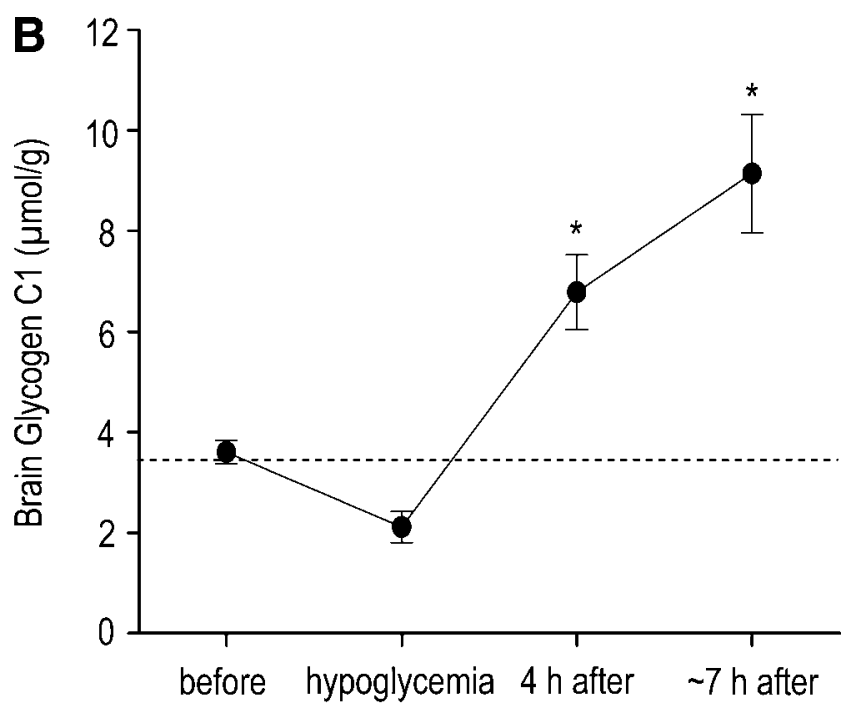

mulation $(\mathrm{LB}=20 \mathrm{~Hz})$. B: Brain glycogen C1 concentrations measured before, during and after hypoglycemia. Repletion of brain glycogen concentrations after hypoglycemia clearly demonstrates excess storage. The glycogen concentration increased by $87 \pm 10 \%(n=7)$ $4 \mathrm{hr}$ after and by $153 \pm 30 \%(n=5) 7 \mathrm{hr}$ after ending hypoglycemia $(\star P<0.01)$. The dashed line indicates the normal euglycemic brain glycogen concentration (Siegel and Agranoff, 1999; Gip et al., 2002; Kong et al., 2002). Error bars indicate standard error.

al., 2001). Clearly, the brain glycogen C1 signal remained observable after $2 \mathrm{hr}$ of hypoglycemia (Fig. 2). The inability to achieve complete depletion of $\left[1-{ }^{13} \mathrm{C}\right]$ glycogen during prolonged periods of hypoglycemia demonstrates that the brain glycogen pool can survive extended periods of hypoglycemia, suggesting that glycogen serves as a significant carbohydrate reservoir during mild hypoglycemia and can account for a partial deficit in glucose supply. In this context, it is interesting to note that brain glucose transport seems to have a low $\mathrm{K}_{\mathrm{m}}$ on the order of 1-3 mM (Gruetter et al., 1998b; Choi et al., 2001; de Graaf et al., 2001; Seaquist et al., 2001), consistent with that of GLUT-1, the ubiquitous glucose transporter at the bloodbrain barrier. Such a low $\mathrm{K}_{\mathrm{m}}$ implies that substantial transport of glucose occurs during hypoglycemia, even when brain glucose concentrations are zero.

Because the average plasma glucose concentration was estimated at $1.5 \mathrm{mM}$ during the hypoglycemic period in our study, the kinetic constants of glucose transport measured for the rat anesthetized under identical conditions as in the present study (Choi et al., 2001) imply a relative glucose consumption deficit of approximately $15 \%$. The average degradation rate of $64 \% / \mathrm{hr}$ of the estimated pre-hypoglycemic concentration amounts to a glycogenolytic flux of $0.038 \pm 0.005 \mu \mathrm{mol} / \mathrm{g} / \mathrm{min}$. This glycogenolytic rate is on the order of $13-15 \%$ of the reported basal glucose consumption rates for the 
$\alpha$-chloralose anesthetized rat (Shulman et al., 1999; Nakao et al., 2001), suggesting that in our experiments, glycogenolysis accounted for a substantial fraction or even all of the glucose supply deficit. Therefore, brain glycogen is likely to play a significant role during hypoglycemia. One possible neuroprotective mechanism of glycogen is to provide ATP to allow continuous uptake of excitotoxic glutamate from the synaptic cleft and to provide lactate as a fuel for neurons (Magistretti and Pellerin, 1996).

Seven hours after resuming the glucose infusion to restore glycemia, ${ }^{13} \mathrm{C}$-labeled brain glycogen concentrations approached $10 \mu \mathrm{mol} / \mathrm{g}$ (Fig. 3B), which is approximately three times the normal brain glycogen concentration of $3.3 \mu \mathrm{mol} / \mathrm{g}$ (Siegel and Agranoff, 1999). Thus our study demonstrates clearly that the brain glycogen levels can exceed the pre-hypoglycemic level after hypoglycemia, as also can be seen from the substantially increased glycogen C1 signal (Fig. 3A). Our results, therefore, for the first time provide direct experimental in vivo data supporting the hypothesis that super-compensation of glycogen in the brain occurs after a single episode of insulininduced hypoglycemia. Because this result is consistent with the observation that a single episode of hypoglycemia can lead to blunting of the counter-regulatory hormones during subsequent hypoglycemia (hypoglycemia unawareness) (Cryer, 1994; Davis et al., 1997; Fanelli et al., 1998), it is possible that glycogen metabolism may be involved in the development of the hypoglycemia unawareness syndrome, as increased glycogen content leads to increased neuronal protection against neuroglycopenia (Dringen and Hamprecht, 1992; Swanson and Choi, 1993).

Because the study relied on measuring ${ }^{13} \mathrm{C}$-labeled glucose and observing ${ }^{13} \mathrm{C}$ incorporation into brain glycogen, it is possible that ${ }^{13} \mathrm{C}$ label cycling (turnover) could confound our measurements. Although this is a distinct possibility, label exchange per se is unlikely to alter the qualitative nature of the observations and the conclusions of this study. To assess whether turnover of the ${ }^{13} \mathrm{C}-$ labeled glycogen pool may alter the conclusions of the present study, we verified the following points.

First, in Group I, labeling of the brain glucose occurred on a similar time scale in the animals receiving insulin compared to those receiving somatostatin. Because these experiments were carried out under conditions of acutely raised glucose, resulting in mild hyperglycemia, the isotopic enrichment of brain glucose rapidly approached that of the infusate $(99 \%)$, which has been our consistent experience in humans (Gruetter et al., 1998a, 2001) and in rats (Choi et al., 2001). Furthermore, because total glycogen is given by the sum of labeled glycogen (denoted by $\left.{ }^{13} \mathrm{Glyc}_{1}\right)$ and unlabeled glycogen $\left({ }^{12} \mathrm{Glyc}_{1}\right)$, i.e., [Glyc] $={ }^{13} \mathrm{Glyc}_{1}+{ }^{12} \mathrm{Glyc}_{1}$, it is obvious that the relationship ${ }^{13} \mathrm{Glyc}_{1}(\mathrm{t})<[\mathrm{Glyc}](\mathrm{t})$ always holds. Hence, the total glycogen concentration in the insulin-treated group $[\mathrm{Glyc}]>{ }^{13} \mathrm{Glyc}_{1}(\mathrm{t})=5.8 \mu \mathrm{mol} / \mathrm{g}$. Therefore, it is obvious that net glycogen synthesis must have occurred, because the amount of quantified ${ }^{13} \mathrm{C}$ label is twofold higher than the total brain glycogen, $[\mathrm{Glyc}]_{0}$, we observed in rats without exogenous insulin infusion (Choi and Gruetter, 2003) and what has been reported as the normal brain glycogen concentration (Siegel and Agranoff, 1999; Gip et al., 2002; Kong et al., 2002). This implies that the total glycogen concentration [Glyc] $(\mathrm{t})$ in the insulintreated group was higher than normal. This is consistent with our earlier study, where we explicitly measured label turnover during glucose infusion, which most likely resulted in additional insulin secretion (Choi et al., 1999). Because the insulin-treated animals in Group I of this study had the highest amount of label incorporation (5.8 $\mu \mathrm{mol} / \mathrm{g}$ ), we propose that serum insulin plays an important role in the regulation of brain glycogen metabolism. There is plausible cause for such an action because insulin has been shown to cross the blood-brain barrier and can act through numerous receptors found in the brain as well as at the blood-brain barrier (Banks et al., 1997).

Second, during hypoglycemia in Group II, it is possible that unlabeled substrate could enter the glycogen pool, thereby leading to an overestimate of the rate of glycogenolysis; however, the $\left[1-{ }^{13} \mathrm{C}\right]$ glucose infusion continued at a reduced rate during hypoglycemia. In addition, it is expected that the flux through glycogen synthase is reduced during hypoglycemia and much lower than under normal conditions. The observed rate of glycogen degradation, however, was several-fold higher (2.3 $\mu \mathrm{mol} / \mathrm{g} / \mathrm{hr}$ ) than the normal turnover rate of glycogen $(0.5 \mu \mathrm{mol} / \mathrm{g} / \mathrm{hr})$ (Choi et al., 1999). Thus, we conclude that label exchange during hypoglycemia is an unlikely explanation of the observed rapid decline in ${ }^{13} \mathrm{C}$-labeled glycogen.

Finally, the ${ }^{13} \mathrm{C}$-labeled brain glycogen concentration observed $7 \mathrm{hr}$ after hypoglycemia was increased, which can, in principle, be due to replacing the unlabeled glucosyl units with labeled glucosyl units (turnover). Label turnover alone, however, cannot account for a $\left[1-{ }^{13} \mathrm{C}\right]$ glycogen concentration that was several-fold higher than the normal brain glycogen concentration (see above). Therefore, we conclude that although turnover can perhaps affect some of the measurements quantitatively, the conclusions drawn from the studies reported herein cannot be explained by turnover alone and hence, net synthesis must have occurred. This is supported further by an early report that brain glycogen may have rebounded after severe hypoglycemia and ischemia in the awake rat brain (Folbergrova et al., 1996). That study did not measure the rate of glycogen depletion during hypoglycemia, however, and thus did not establish further the importance of brain glycogen as a potential store of glucose during the more moderate hypoglycemia studied here.

In addition to glycogen, amino acids and lactate can serve as fuels during insulin-induced hypoglycemia. Our estimation that overall ATP production due to glycogenolysis covers much of the glucose deficit during hypoglycemia further implies that amino acids are not a major component of fuel usage during moderate hypoglycemia, which is consistent with the observation that amino acid concentrations were rather constant (data not shown). 
This observation was also consistent with the observation that amino acid depletion occurs when $\mathrm{PCr}$ is decreasing, which was not observed in the present study and has been reported at plasma glucose concentrations of approximately $1 \mathrm{mM}$ and below in the awake rat, substantially lower than those maintained during our experiments (Agardh et al., 1978). Our levels of plasma glucose during hypoglycemia were typically higher, corresponding to more moderate hypoglycemia. Furthermore, even though light anesthesia was used in the present study, a reduction of the cerebral glucose metabolic rate compared to these early studies is likely and thus the point at which $\mathrm{PCr}$ is depleted may have been shifted to below $1 \mathrm{mM}$. Conversely, it is likely that brain glycogen would become depleted in the awake animal at a much higher plasma glucose concentration, which further underscores the importance of brain glycogen as a neuroprotective glucose store.

The observations in our study also shed light on the proposed use of lactate as neuronal metabolic fuel. During hypoglycemia, when glucose transport across the bloodbrain barrier becomes rate limiting for cellular metabolism, brain glycogen, found exclusively in astrocytes in the adult brain, can provide a substantial fraction of the fuel deficit for extended periods. Because most of the oxidative carbohydrate metabolism in vivo is in neurons (Gruetter et al., 2001), it is likely that glycogen-derived fuel is metabolized to pyruvate. Pyruvate, a substrate that is extensively metabolized by neurons, can easily be converted to lactate in glia. This supports the postulation that glial-derived lactate is a significant source of fuel for neurons under stimulated conditions (Dringen et al., 1993; Magistretti et al., 1993; Alves et al., 1995; Griffin et al., 1999). Alternatively, astrocytic glycogen may provide fuel to allow continued glutamate uptake into astrocytes and conversion to glutamine to reduce hypoglycemic brain injury through reduced glutamate excitotoxicity. Therefore, an understanding of the regulation of brain glycogen metabolism is key in providing insights into brain energy metabolism with respect to the neuronal-astrocytic metabolic relationship.

\section{CONCLUSIONS}

We conclude that acute hyperinsulinemia has a strong effect on brain glycogen metabolism leading to net glycogen synthesis. From the slow rate of glycogen depletion and the apparent inability of prolonged hypoglycemia to deplete glycogen completely, we conclude that brain glycogen can provide glucosyl units for extended periods during moderate hypoglycemia, and that glycogenolysis can account for the majority of the glucose deficit. The evidence in this study supports the hypothesis that posthypoglycemic can exceed pre-hypoglycemic glycogen concentrations several-fold, providing excessive glucosyl storage that potentially may interfere with the ability of glucose-sensing and glucose-responsive neurons to recognize hypoglycemia during subsequent hypoglycemic episodes. Therefore, we postulate that brain glycogen may play a significant neuroprotective role in vivo and that glycogen metabolism may be involved in the pathogenesis of hypoglycemia unawareness after hypoglycemic episodes observed in patients with diabetes mellitus.

\section{ACKNOWLEDGMENTS}

This work was supported by NIH (R21DK58004, R01NS42005 to R.G.) and by the Juvenile Diabetes Research Foundation (R.G.) and a Grant-in-Aid by the University of Minnesota Graduate School (R.G.). The Center for Magnetic Resonance Research is supported in part by a grant from the Biotechnology Regional Resource Center program of the NCRR (P41RR08079) and the $9.4 \mathrm{~T}$ instrument was supported in part by a gift from the W.M. Keck Foundation.

\section{REFERENCES}

Adriany G, Gruetter R. 1997. A half volume coil for efficient proton decoupling in humans at 4 Tesla. J Magn Reson 125:178-184.

Agardh CD, Folbergrova J, Siesjo BK. 1978. Cerebral metabolic changes in profound, insulin-induced hypoglycemia, and in the recovery period following glucose administration. J Neurochem 31:1135-1142.

Alves PM, McKenna MC, Sonnewald U. 1995. Lactate metabolism in mouse brain astrocytes studied by 13C NMR spectroscopy. Neuroreport 6:2201-2204.

Amiel SA. 1998. Ernst-Friedrich-Pfeiffer-Memorial lecture. Hypoglycaemia associated syndrome. Acta Diabetol 35:226-231.

Banks WA, Jaspan JB, Kastin AJ. 1997. Effect of diabetes mellitus on the permeability of the blood-brain barrier to insulin. Peptides 18:1577-1584. Boyle PJ, Nagy RJ, O’Connor AM, Kempers SF, Yeo RA, Qualls C. 1994. Adaptation in brain glucose uptake following recurrent hypoglycemia. Proc Natl Acad Sci USA 91:9352-9356.

Choi I-Y, Gruetter R. 2003. In vivo ${ }^{13} \mathrm{C}$ NMR assessment of brain glycogen concentration and turnover in the awake rat. Neurochem Int (in press).

Choi I-Y, Lee S-P, Kim S-G, Gruetter R. 2001. In vivo measurements of brain glucose transport using the reversible Michaelis-Menten model and simultaneous measurements of cerebral blood flow changes during hypoglycemia. J Cereb Blood Flow Metab 21:653-663.

Choi I-Y, Tkac I, Gruetter R. 2000. Single-shot, three-dimensional "nonecho" localization method for in vivo NMR spectroscopy. Magn Reson Med 44:387-394.

Choi I-Y, Tkac I, Ugurbil K, Gruetter R. 1999. Noninvasive measurements of [1-(13)C] glycogen concentrations and metabolism in rat brain in vivo. J Neurochem 73:1300-1308.

Clarke DD, Sokoloff L. 1999. Circulation and energy metabolism of the brain. In: Siegel GJ, Agranoff BW, Albers RW, Fisher SK, Uhler MD, editors. Basic neurochemistry: molecular, cellular and medical aspects. Philadelphia: Lippincott-Raven. p 638-640.

Cryer PE. 1994. Banting Lecture. Hypoglycemia: the limiting factor in the management of IDDM. Diabetes 43:1378-1389.

Daniel PM, Love ER, Pratt OE. 1977. The influence of insulin upon the metabolism of glucose by the brain. Proc R Soc Lond B Biol Sci 196:85-104.

Davis SN, Shavers C, Mosqueda-Garcia R, Costa F. 1997. Effects of differing antecedent hypoglycemia on subsequent counterregulation in normal humans. Diabetes 46:1328-1335.

de Graaf RA, Pan JW, Telang F, Lee JH, Brown P, Novotny EJ, Hetherington HP, Rothman DL. 2001. Differentiation of glucose transport in human brain gray and white matter. J Cereb Blood Flow Metab 21:483492.

Dringen R, Gebhardt R, Hamprecht B. 1993. Glycogen in astrocytes: possible function as lactate supply for neighboring cells. Brain Res 623: 208-214. 
Dringen R, Hamprecht B. 1992. Glucose, insulin, and insulin-like growth factor I regulate the glycogen content of astroglia-rich primary cultures. J Neurochem 58:511-517.

Fanelli CG, Pampanelli S, Porcellati F, Bolli GB. 1998. Shift of glycaemic thresholds for cognitive function in hypoglycaemia unawareness in humans. Diabetologia 41:720-723.

Folbergrova J, Katsura KI, Siesjo BK. 1996. Glycogen accumulated in the brain following insults is not degraded during a subsequent period of ischemia. J Neurol Sci 137:7-13.

Gerich JE, Mokan M, Veneman T, Korytkowski M, Mitrakou A. 1991. Hypoglycemia unawareness. Endocr Rev 12:356-371.

Gip P, Hagiwara G, Ruby NF, Heller HC. 2002. Sleep deprivation decreases glycogen in the cerebellum but not in the cortex of young rats. Am J Physiol Regul Integr Comp Physiol 283:54-59.

Gorski J, Palka P, Puch U, Kiczka K. 1976. The post-exercise glycogen recovery in tissues of trained rats. Acta Physiol Pol 27:47-53.

Griffin JL, Rae C, Radda GK, Matthews PM. 1999. Delayed labelling of brain glutamate after an intra-arterial [13C]glucose bolus: evidence for aerobic metabolism of guinea pig brain glycogen store. Biochim Biophys Acta 1450:297-307.

Gruetter R, Seaquist ER, Kim S, Ugurbil K. 1998a. Localized in vivo 13C NMR of glutamate metabolism: initial results at 4 Tesla. Dev Neurosci 20:380-388.

Gruetter R, Seaquist ER, Ugurbil K, 2001. A mathematical model of compartmentalized neurotransmitter metabolism in the human brain. Am J Physiol 281:100-112.

Gruetter R, Tkac I. 2000. Field mapping without reference scan using asymmetric echo-planar techniques. Magn Reson Med 43:319-323.

Gruetter R, Ugurbil K, Seaquist ER. 1998b. Steady-state cerebral glucose concentrations and transport in the human brain. J Neurochem 70:397408.

Kerr SE, Ghantus M. 1936. The carbohydrate metabolism of brain. II. The effect of varying the carbohydrate and insulin supply on the glycogen, free sugar and lactic acid in mammalian brain. J Biol Chem 116:9-19.

Kong J, Shepel PN, Holden CP, Mackiewicz M, Pack AI, Geiger JD. 2002. Brain glycogen decreases with increased periods of wakefulness: implications for homeostatic drive to sleep. J Neurosci 22:5581-5587.

Kumagai AK, Kang YS, Boado RJ, Pardridge WM. 1995. Upregulation of blood-brain barrier GLUT1 glucose transporter protein and mRNA in experimental chronic hypoglycemia. Diabetes 44:1399-1404.

Lewis LD, Ljunggren B, Norberg K, Siesjo BK. 1974. Changes in carbohydrate substrates, amino acids and ammonia in the brain during insulininduced hypoglycemia. J Neurochem 23:659-671.

Magistretti PJ, Pellerin L. 1996. Cellular bases of brain energy metabolism and their relevance to functional brain imaging: evidence for a prominent role of astrocytes. Cereb Cortex 6:50-61.

Magistretti PJ, Sorg O, Yu N, Martin JL, Pellerin L. 1993. Neurotransmitters regulate energy metabolism in astrocytes: implications for the metabolic trafficking between neural cells. Dev Neurosci 15:306-312.
Mitrakou A, Ryan C, Veneman T, Mokan M, Jenssen T, Kiss I, Durrant J, Cryer P, Gerich J. 1991. Hierarchy of glycemic thresholds for counterregulatory hormone secretion, symptoms, and cerebral dysfunction. Am J Physiol 260:67-74.

Nakao Y, Itoh Y, Kuang T, Cook M, Jehle J, Sokoloff L. 2001. Effects of anesthesia on functional activation of cerebral blood flow and metabolism. Proc Natl Acad Sci USA 98:7593-7598.

Nelson SR, Schulz DW, Passonneau JV, Lowry OH. 1968. Control of glycogen levels in brain. J Neurochem 15:1271-1279.

Norberg K, Siesjo BK. 1976. Oxidative metabolism of the cerebral cortex of the rat in severe insulin-induced hypoglycaemia. J Neurochem 26:345352.

Pelligrino DA, LaManna JC, Duckrow RB, Bryan RM Jr, Harik SI. 1992. Hyperglycemia and blood-brain barrier glucose transport. J Cereb Blood Flow Metab 12:887-899.

Pfeuffer J, Tkac I, Provencher SW, Gruetter R. 1999. Toward an in vivo neurochemical profile: quantification of 18 metabolites in short-echotime (1)H NMR spectra of the rat brain. J Magn Reson 141:104-120.

Poland JL, Trauner DA. 1973. Adrenal influence on the supercompensation of cardiac glycogen following exercise. Am J Physiol 224:540-542.

Richter EA, Derave W, Wojtaszewski JF. 2001. Glucose, exercise and insulin: emerging concepts. J Physiol 535:313-322.

Rossetti L, Giaccari A, Barzilai N, Howard K, Sebel G, Hu M. 1993. Mechanisms by which hyperglycemia inhibits hepatic glucose production in conscious rats. Implications for the pathophysiology of fasting hyperglycemia in diabetes. J Clin Invest 92:1126-1134.

Seaquist ER, Damberg GS, Tkac I, Gruetter R. 2001. The effect of insulin on in vivo cerebral glucose concentrations and rates of glucose transport/ metabolism in humans. Diabetes 50:2203-2209.

Shulman RG, Rothman DL, Hyder F. 1999. Stimulated changes in localized cerebral energy consumption under anesthesia. Proc Natl Acad Sci USA 96:3245-3250.

Siegel GJ, Agranoff BW. 1999. Basic neurochemistry: molecular, cellular and medical aspects. Philadelphia: Lippincott-Raven.

Simpson IA, Appel NM, Hokari M, Oki J, Holman GD, Maher F, Koehler-Stec EM, Vannucci SJ, Smith QR. 1999. Blood-brain barrier glucose transporter: effects of hypo- and hyperglycemia revisited. J Neurochem 72:238-247.

Strang RH, Bachelard HS. 1971. Effect of insulin on levels and turnover of intermediates of brain carbohydrate metabolism in vivo. J Neurochem 18:1799-1807.

Swanson RA, Choi DW. 1993. Glial glycogen stores affect neuronal survival during glucose deprivation in vitro. J Cereb Blood Flow Metab 13:162-169.

Tkac I, Starcuk Z, Choi I-Y, Gruetter R. 1999. In vivo 1H NMR spectroscopy of rat brain at $1 \mathrm{~ms}$ echo time. Magn Reson Med 41:649656.

van de Werve G, Jeanrenaud B. 1987. Liver glycogen metabolism: an overview. Diabetes Metab Rev 3:47-78. 